\title{
Compliance, noncompliance, and the in-between: causal effects of civilian demeanor on police officers' cognitions and emotions
}

\author{
Justin Nix ${ }^{1}$ (D) Justin T. Pickett ${ }^{2} \cdot$ Renée J. Mitchell ${ }^{3}$ \\ Published online: 2 July 2019 \\ (C) The Author(s) 2019
}

\section{Abstract}

Objectives Police legitimacy can hinge on what happens in police-civilian encounters, yet much remains unknown about the socio-psychological processes involved in these bilateral interactions, especially those affecting officers. We integrate insights from policing research with theories and findings from scholarship on moral psychology, interpersonal strain, and victimization fear to develop hypotheses about the situational effects of civilian demeanor on officers' cognitions (suspicion and perceived danger) and emotions (anger, frustration, annoyance, and fear).

Methods We administered a series of three randomized vignettes involving routine policecivilian encounters to 546 officers working in a large city in the southwestern United States. We randomized civilian behavior - compliant, bad attitude (compliant but disrespectful), or noncompliant — and the encounter type - offense-based versus dispatch-initiated.

Results Demeanor exerts a large causal effect on what officers think and feel in policecivilian encounters. In each experiment, civilian hostility and disrespect increased officers' self-reported suspicion, perceived danger, and antagonistic emotions (anger, frustration, and annoyance). In some cases, it also increased their fear.

Conclusions Each of these cognitions and emotions may separately influence police decision-making, and each carries unique policy implications. Our results also suggest the efficacy of experimental surveys to unpack the dynamics of police-civilian interactions.

Keywords Decision-making $\cdot$ Demeanor $\cdot$ Discretion $\cdot$ Emotions $\cdot$ Policing

\section{Introduction}

In today's society where policing is increasingly visible and salient (Weitzer 2015), whether people view the law as legitimate and trust in legal institutions can hinge on

Justin Nix

jnix@unomaha.edu

Extended author information available on the last page of the article 
what police officers do when faced with one of their most difficult and dangerous tasks: interacting with civilians (Mazerolle et al. 2013; Tyler and Jackson 2014). The two most important decisions in these interactions are connected (Reiss 1971; Sykes and Clarke 1975). Civilians decide how they will behave toward police officers, and officers decide how they will exercise their authority. After choosing to intervene (e.g., make a traffic stop), officers choose how to handle the interaction as it unfolds, and their choices can range from issuing a verbal warning to using deadly force. Although many factors influence whether (and how) officers decide to invoke their authority and take punitive actions (e.g., make an arrest), civilians' demeanor appears to be especially consequential (Mastrofski et al. 2002). When civilians are disrespectful or hostile, it increases their likelihood of being ticketed (Worden and Shepard 1996), arrested (Engel et al. 2010; Novak and Engel 2005), and subdued by force (Alpert and Dunham 2004; Engel et al. 2000). Officers may also be less likely to use verbal deescalation tactics with civilians who are disrespectful or hostile (James et al. 2018).

One lingering question is whether these relationships occur because of the causal effects of civilian demeanor, noncompliance, or both (Klinger 1994, 1996; Worden et al. 1996). Demeanor is "legally permissible behavior of civilians during interactions with police that indicates the degree of deference or respect they extend to involved officers" (Klinger 1994: 477, emphasis in original), whereas noncompliance is a failure to follow lawful orders (Engel et al. 2012), which itself may be a crime in many jurisdictions. It is hard to identify the separate effects of demeanor and noncompliance by observing actual police-civilian interactions for two reasons. First, we cannot cleanly isolate the behavioral choices of each actor from the other or from the outcome of the encounter. When interacting, officers and civilians continuously influence each other, sometimes in subtle ways, and compliance decisions can be either a cause or an effect of this dynamic interactive process (Reisig et al. 2004; Worden and McLean 2017). Second, demeanor is correlated with a host of variables - like race, criminal context, and the neighborhood environment (Reisig et al. 2004; Smith and Alpert 2007) - that might also influence officers (Klinger 1994, 1996). And officers' individual-level characteristics - their race, past experiences, etcetera-also affect how they perceive civilians' behavior and choose to exercise their discretion (Engel et al. 2012). Unfortunately, most of the evidence for demeanor effects comes from observational research (Black and Reiss 1970; Dunham and Alpert 2009; Lundman 1974; Piliavin and Briar 1964; Smith 1984), in which parsing out the effects of hostility or disrespect versus noncompliance and other factors is exceedingly difficult and requires strong modeling assumptions. ${ }^{1}$ A few experimental studies exist (e.g., Bennett 1976; Nix et al. 2019), but they have not separately manipulated demeanor and compliance.

There is another lingering question, one that is elementary but fundamental: How does demeanor impact officer decision-making? That is, what are the sociopsychological effects of civilian disrespect on officers in encounters? When a civilian has a bad attitude, does it signal pertinent information to the officers involved,

\footnotetext{
${ }^{1}$ One principal assumption is that the model controls for all common causes of demeanor and the outcome variable (e.g., arrest) (Klinger 1994). The problem in observational studies is that researchers can control only for confounders that they know about and measure (Shadish et al. 2002). And even when all the relevant variables are included in the model, confounding bias may still exist if there is any measurement error in those control variables (Westfall and Yarkoni 2016).
} 
influencing what they think about the person-for example, that he or she is suspicious or dangerous? Or does disrespect affect how the officers feel about the situation-their level of frustration, anger, or fearfulness? Unfortunately, the available evidence provides few answers. Most prior research has focused on the outcomes of police-civilian interactions - such as arrests or the use of force. As a consequence, what goes on in officers' heads when they encounter disrespectful and hostile civilians remains a black box. Yet, knowing what officers think and feel in these situations is critical for advancing theories of police decision-making and identifying effective policies for improving how officers make decisions when interacting with civilians (Engel et al. 2012).

There are two reasons why the socio-psychological effects of demeanor on officers have escaped empirical attention. The first is that our field lacks a theoretical framework for studying demeanor that identifies those cognitions and emotions most theoretically germane to officer decision-making (Pickett and Nix 2019). The second reason is methodological. Researchers examining the effects of demeanor on officers' behavior have come to rely on a method - systematic social observation - that is ill-suited for measuring officers' attitudes and emotions, limiting the scope of their analyses. We address these issues in the current study. We theorize why and how demeanor affects officers, assess the existing observational evidence for demeanor effects as well as its limitations, and report new evidence from experiments that focused on officers' attitudes and emotions, rather than behaviors. In the experiments, we randomized both demeanor and compliance. The results show that independent of compliance, demeanor exerts large causal effects on officers' cognitions and emotions; it influences not just what officers think but also how they feel when interacting with civilians.

\section{Theorizing the situational and socio-psychological effects of demeanor}

When questioned directly, police officers say they are more likely to arrest civilians who have bad attitudes (Weisburd et al. 2000). This survey evidence is consistent with the longstanding conclusion from ethnographic research that demeanor is central to how officers decide to handle situations. In one of the earliest studies, William Westley $(1953,1970)$ shed light on the importance officers place on being respected by civilians and revealed that a significant portion $-37 \%$ of those he asked, the modal responsebelieved the appropriate response to those who are disrespectful is to use coercive force. Brown (1988: 196) came to a similar conclusion about how officers respond when civilians fail the "attitude test." But separate from legal compliance, why would demeanor be important to officers, and why might they want to respond coercively to disrespectful civilians? There are several theoretical possibilities.

One possibility is that demeanor may affect officers' cognitions (Bayley 1995; Toch 1996). When civilians are disrespectful or hostile, even if they comply with any initial police orders, it may influence officers' perceptions of their character or expectations about what will happen next in encounters. A half century ago, Jerome Skolnick (1966: 41) observed, "the element of danger seems to make the police officer especially attentive to signs indicating a potential for violence and lawbreaking." Consequently, he argued, police view civilian hostility as a danger signifier, arousing their suspicion. Likewise, Miller (2004: 36) argued that the police believe disrespectful civilians "pose 
a greater danger" to them; in the officer's view, "an asshole who disrespects a cop is capable of anything." Theoretically, then, civilian disrespect and hostility should increase suspicion and perceived risk among officers. In turn, an officer's cognitive assessment that a civilian is suspicious or dangerous may create a perceived need to gain control over the situation quickly and decisively. Indeed, the "reactive hypothesis" of danger perception theory emphasizes the importance of threat perceptions for understanding officer decision-making. It holds that the prevailing level of perceived risk among officers affects their use of force (Jacobs and O'Brien 1988; MacDonald et al. 2001). Danger perception theory focuses on the sensitivity of threat perceptions to extra-situational factors (e.g., local or national homicide rates), but demeanor may be a situational cause of perceived risk.

If officers view civilian disrespect as a proxy for suspiciousness or dangerousness, it is also possible that they will become more fearful when faced with disrespectful civilians (Holmes and Smith 2012). Fear is an emotion that is distinct from one's cognitive assessment of risk (Ferraro 1995; Pickett et al. 2018a). Fear is a function of three types of perceptions: risk (or likelihood), control, and severity (of outcomes) (Jackson 2011). In other words, people are most fearful when they believe that some negative event, like an attack or victimization, is likely to occur, that it is unpredictable or uncontrollable, and that it will have severe consequences. Fear profoundly affects behavior (Pickett et al. 2018a; Warr 2009). Experiencing fear produces a strong motivation to take behavioral steps to reduce risk, such as avoiding dangerous people or places (Jackson and Gray 2010). Yet, "police officers rarely have the option of fleeing danger - their job demands that they confront society's dangerous citizens" (Holmes and Smith 2012: 350). Consequently, if officers experience situational fear in response to disrespectful civilians, perhaps because disrespect creates a sense of unpredictability, it may provoke them to take punitive actions to control encounters (Berkowitz 1993). Indeed, Holmes and Smith (2012: 347) argue that, at least in high-crime areas of the community, fear is "always relatively close to the surface, ready to take hold of a police officer's conduct."

Beyond perceived risk and fear, demeanor may also influence officer decisionmaking through other channels. According to Reiss (1971: 136), demeanor is imbued with moral significance, and officers experience "moral indignation ... from the failure of an offender to grant deference to police authority." Becker (1963) argued that officers view disrespectful civilians as morally deserving of sanctions (see also Black's 1976 discussion of "moral worthiness"). What makes disrespectful behavior so consequential is that it "signifies defiance of the larger social institutions the officer represents" (Miller 2004: 36). According to Bayley (1995:101), officers view themselves as "the last best hope for order" in society, and thus believe "people who treat them with disrespect constitute a serious threat to order"; from the officers" perspective, a bad attitude is a "symbolic attack on the law itself." Van Maanen (1978:316) made the same observation, noting that officers believe much of their job involves dealing with "certifiable asshole(s)" whose affronts, however subtle, officers take as an indication "that their position and authority in the interaction are not being taken seriously." He too emphasized that because of the sense officers have of "their moral position and responsibility," they see disrespect as more than just an individual slight - to them it is "a profaning of the social and legal system," which they perceive as "a moral transgression" (pp. 313-319). 
If officers view a bad attitude as a moral transgression, then they may experience antagonistic emotions such as anger when interacting with disrespectful civilians. A large body of research in the field of moral psychology, using diverse methodologies, shows that perceived moral violations trigger "moral outrage," followed by an urge to punish the violator (Darley 2009; Miller 2001). The strongest evidence comes from experimental games, wherein participants can win or lose money, and have opportunities to punish transgressions (e.g., cheating, unfair offers) by other participants. Neurological imaging suggests that participants experience antagonistic emotions in response to these transgressions, as evidenced by activation of the bilateral anterior insula (Sanfey et al. 2003). In turn, participants get satisfaction or even pleasure from punishing rule breakers, which is shown by increased activity in the caudate nucleus (de Quervain et al. 2004). In fact, even third-party participants who observe others playing experimental games have shown a willingness to spend their own in-game earnings to experience the satisfaction of punishing rule breakers (Fehr and Fischbacher 2004; Kahneman et al. 1986). Other experimental evidence demonstrates that participants report feeling emotions like anger in response to unpunished moral transgressions, but report few such emotions if the offenders are punished (Pickett and Baker 2017). Although none of this research has focused on police-civilian interactions, the findings nonetheless suggest that disrespect could have similar effects on officers. Outright noncompliance should too, of course.

Finally, even lacking moral significance, civilian disrespect may provoke in officers a range of negative emotions like anger, frustration, and annoyance merely because it constitutes a type of interpersonal strain (Paoline and Gau 2018): the presentation of "noxious or negatively valued stimuli" (Agnew 1992: 50). In fact, scholars have long argued that cynical and authoritarian attitudes develop among officers as a cultural adaptation to the strains associated with police work (Brown 1988; Paoline 2003, 2004), especially the strain of dealing with disrespectful and hostile civilians (Skolnick 1966; Toch 1996; Wilson 1967). Paoline and Gau (2018) recently reported observational evidence in support of this argument, finding that stress was associated with increased adherence to the police subculture. Another recent observational study found that a cumulative measure of organizational strain - the self-reported frequency of experiencing different stressful events (e.g., "receiving negative comments from the public," "dealing with supervisors," "working more than 40 hours per week") during the previous 6 months - was associated with higher levels of general anger among officers while on duty (Bishopp et al. 2018: 7). However, civilian disrespect and hostility is a type of strain that may also have situational effects, increasing officers' anger and frustration toward specific civilians within individual encounters. We provide the first test of this possibility in the current study.

\section{Prior research on demeanor effects}

Scholarship on demeanor has followed an unusual path: researchers first examined demeanor effects on officer behavior, then later focused on how to conceptualize demeanor, and only recently began testing causal mechanisms (Nix et al. 2017; Pickett and Nix 2019). Studies looking at how demeanor affects officer behavior relied mostly on data collected via systematic social observation, limiting their ability to analyze attitudinal or emotional mechanisms. Their main finding was that officers are 
more likely to take punitive actions - such as ticketing, searching, arresting, or using force - against civilians who are hostile or disrespectful (Lundman 1994, 1996; Piliavin and Briar 1964). Some research also found that demeanor influences other. nonpunitive officer behaviors as well. Mastrofski et al. (2002), for example, reported that officers were less likely to be respectful of civilians with bad attitudes. On the other hand, Mastrofski et al. (2016: 132) examined the predictors of officers' use of procedural justice in encounters and found an "absence of significant effects for ... displays of citizen respect and disrespect." But taken as a whole, the evidence to date appears to suggest that officers treat people differently based, at least in part, on their demeanor.

Unfortunately, it is difficult to draw firm conclusions about the causal effects of demeanor on the basis of this literature for six reasons (Klinger 1994). First, “observers' characterizations of suspects' demeanor are only as valid as the instructions given to observers and the judgments that they make" (Worden et al. 1996: 329). The second reason dovetails with the first: because the conceptualization of demeanor took a backseat to research on it, many scholars have conflated hostile demeanor with criminal offenses such as assaulting officers. The problem is that "demeanor is not regulated by criminal statute" - a civilian has a bad demeanor if he or she is disrespectful or hostile but "violates no laws" (Klinger 1994: 477-478). The third is reactivity; the presence of observers may change the relationships of interest if it affects how officers respond to civilians, and there is evidence that it does (Spano 2005, 2006).

A fourth reason is that researchers using observational data have often been unable to establish the temporal order of events in police-civilian encounters (Klinger 1994, 1996). As Reiss (1971: 48) lamented, “it is difficult to determine whether an officer's or citizen's behavior initiated the tone or action in the encounter." And as Klinger (1994) noted, in many observational studies, it is not even clear whether the observers measured demeanor before or after an arrest. Fifth, any study of demeanor has to control for all pre-interaction offenses as well as any relevant information the officers may have about the suspect (e.g., whether the suspect has an outstanding warrant, is a repeat offender) (Klinger 1994, 1996). Most prior studies either have not done this, or have used only coarse measures of offending. Sixth, researchers must control for any crimes (property, violent, or drug) committed (or discovered) during the encounter, which is rarely possible with observational data.

Klinger (1994) addressed some but not all of these issues in his analysis of observational data collected in Miami-Dade in the 1980s — wherein he measured demeanor on a three-point ordinal scale that solely captured legal behaviors - and found that the effect of demeanor on arrest was statistically nonsignificant upon controlling for criminal behavior. Mastrofski et al. (1995) reached a similar conclusion shortly thereafter in their 1992 study of police-citizen encounters in Richmond, VA: the effect of legal resistance on officers' decision to arrest was rendered nonsignificant upon coding illegal resistance as a serious offense. Other researchers, responding to Klinger's (1994) criticisms, have reanalyzed previously used datasets using different approaches in coding and analyzing the data. The new findings, according to these scholars, suggested, "the conclusion that a hostile demeanor affects police behavior is not contingent ... on how demeanor is measured" (Worden and Shepard 1996: 99; see also Lundman 1996). However, in his reanalysis, Klinger (1996: 72) found that only one measure of demeanor, "extreme hostility," had a significant effect on officers' behavior, and he questioned the meaning of this effect, pointing out that it was delete- 
one sensitive (it hinged on a single observation) and possibly spurious (due to his inability to control for "whether officers had knowledge that citizens were wanted for crimes that preceded the ... intervention").

To say the least, then, observational evidence of demeanor effects remains unconvincing to some scholars. Their skepticism is understandable. In research using observational data, the difficulty of establishing the temporal sequence of officer and civilian behaviors, of disentangling the effects of legal and illegal behaviors, and of ruling out potential confounders raises concerns about the internal validity of findings. For example, how do officers perceive a civilian action that could be categorized as both disrespectful and noncompliant, versus one that is only disrespectful? If a civilian is simultaneously disrespectful and noncompliant, and an officer responds with some level of coercive force, was it the perceived lack of respect or lack of compliance that sparked his response? Indeed, to assume post-hoc "that officers interpret and act on such behavior only in terms of its illegality will obscure rather than illuminate the causal mechanisms that we seek to understand" (Worden et al. 1996: 327).

Perhaps most importantly, observational studies are limited in their ability to look into the black box, to examine what officers are thinking and feeling during interactions with civilians. As Worden et al. (1996: 330) explained, "progress may be made through research that generates insights into how suspects' demeanor is perceived and enters into officers' decision calculus." But such research is not possible with the typical approach of relying on data from observers. This is because cognitions and emotions, unlike observable behaviors, are difficult to measure using systematic social observation.

A more promising approach is to utilize experimental methods, which also make it possible to address the other common limitations of demeanor research (see above). Experimenters can control for pre-interaction and interaction phase crime by design, isolate, and randomly manipulate variables of interest - enhancing internal validity and strengthening causal inferences (Shadish et al. 2002) _ and also measure officers' thoughts and feelings. Unfortunately, experimental studies of the effects of civilian demeanor are rare, and those that do exist have not separately manipulated civilian disrespect and compliance. Indeed, to our knowledge, there are only three relevant experimental studies, one dated - conducted over 40 years ago - and two recent. However, none of the experiments examined officers' emotions (e.g., anger, fear), and only two explored their cognitions (e.g., perceived danger).

Bennett (1976) randomly flashed a life-size image of an "aggressive" or "passive" individual on a screen to police officers, and found they perceived a greater threat to their wellbeing when the individual looked aggressive. The problem is that appearance on its own is an inadequate measure of demeanor. To officers, Westley (1970: 123) explained, the disrespectful civilian is a "wise guy,' the fellow who thinks he knows more than [police] do, the fellow who talks back, the fellow who insults the policeman" (emphasis added). Thus, while it is plausible that individuals can look disrespectful, arguably more salient to officers is what they say and do.

In this vein, two recent experimental studies have used better measures of demeanor. Nix et al. (2019: 1183) presented police officers from two agencies with text vignettes that randomly assigned demeanor based on civilians' actions (e.g., walking off) and words (e.g., cussing), and found officers placed less importance on treating 
disrespectful civilians with procedural fairness. The authors additionally found that officers perceived a greater likelihood of violence in interactions involving disrespectful civilians. However, this study did not isolate compliance from demeanor, making it unclear which of the two was responsible for the observed effects. James et al. (2018) conducted an experimental test of the demeanor hypothesis by randomizing civilian behavior in video simulations with 50 police officers. They focused on one behavioral outcome: verbal de-escalation tactics. Their findings showed that officers were less likely to use verbal de-escalation with confrontational on-screen civilians. However, the evidence in this experiment could not speak to what the officers were thinking or feeling when they encountered confrontational civilians or why they became disinclined to use verbal de-escalation. The important question that remains unanswered is: What specific effects does civilian demeanor have on officers' cognitions or emotions that could lead to a disinclination to use verbal de-escalation, as well as any number of other outcomes (e.g., use of force, arrest)?

\section{The current study: peering into the black box of officer decision-making}

With regard to the role of demeanor in police-civilian interactions, what we know least about is the key causal mechanisms - the myriad cognitive and emotional processesthat drive officer decision-making. As Engel et al. (2012) emphasized, it is critical to understand how officers perceive and react to different types of civilian behavior. Therefore, in this study, we return to the basics, so to speak, focusing on the theoretical fundamentals. We examine experimentally the effects of demeanor and noncompliance on officers' cognitions and emotions. We test the following four hypotheses:

$\mathrm{H}_{1}$ : Disrespectful civilians will arouse greater suspicion among officers than respectful civilians, independent of legal compliance.

$\mathrm{H}_{2}$ : Independent of legal compliance, disrespectful civilians will evoke more antagonistic emotions (i.e., anger, annoyance, frustration) among officers than respectful civilians.

$\mathrm{H}_{3}$ : Officers will be more fearful of civilians who are disrespectful than those who are respectful, independent of legal compliance.

$\mathrm{H}_{4}$ : Relative to respectful civilians, officers will perceive a greater risk of danger when dealing with disrespectful civilians, independent of legal compliance.

\section{Methodology}

\section{Data}

To test our hypotheses, we conducted a series of survey-based experiments with sworn employees of an agency in a large city in the US southwest. At the time of the survey, the agency was comprised of 1752 sworn law enforcement officers and approximately 900 support personnel. It has jurisdiction over one of the 100 most populous cities in the USA — with a population of over 250,000 according to 2016 American Community Survey (ACS) 5-year estimates. The city is also rapidly growing: its population 
increased by approximately $17 \%$ from 2010 to $2016 .^{2}$ Sixty-eight percent of residents are white, $8 \%$ are black, $6 \%$ are Asian, and the remainder belong to some other race. One-third of the population is of Hispanic or Latino decent. According to the Federal Bureau of Investigation's Uniform Crime Report, the overall violent crime rate in the metropolitan statistical area increased slightly from 2014 to 2016, whereas the property crime rate declined.

In choosing an appropriate sampling design and survey mode, we took into account two important and related concerns that arise when surveying police officers: social desirability bias and the necessity of anonymity (Skogan 2015). "Police [are] a suspicious bunch," Skogan (2015: 112) explained, and in in-person interviews, "some [are] certain to fear that 'calls' would be made to discuss their answers with 'higherups." In fact, of all survey modes, in-person surveys with interviewers produce the highest level of social desirability bias (Tourangeau and Yan 2007). Computerized selfadministered surveys yield the lowest (Tourangeau et al. 2013). Therefore, we used the latter mode.

In January 2018, we invited all 1752 sworn employees to participate in an anonymous online survey. An executive lieutenant sent two initial email invitations on our behalf: one to command staff and the other to all of the sergeants. The lieutenant's email included a brief description of the survey (i.e., it was being conducted by academic researchers; respondents would be asked to imagine a variety of scenarios and answer questions about how they would feel in each), a web link, and in the case of the email to the sergeants, a request that they invite their subordinates to participate. No incentives were offered for participation due to the difficulty of delivering incentives in anonymous email surveys (Tourangeau et al. 2013). Following Dillman et al.'s (2014) recommendations for fielding online surveys, we sent three reminder emails over the next 2 weeks, with the data collection period ending in early February. The research protocol was approved by the first author's Institutional Review Board.

Although social desirability bias is lowest in computerized self-administered surveys, so too are response rates (Tourangeau et al. 2013). Add to this the large decline in response rates to police surveys over the past decade (Nix et al. 2019), and it is easy to see why computerized surveys of police officers have tended to obtain very low response rates: 20\% (Nix and Pickett 2017), 21\% (Donner et al. 2016), 25\% (Skogan 2015), 28\% (Reynolds and Helfers 2017), and "just over 30\%" (Bradford and Quinton 2014: 1032). Similar to this literature, 546 out of the 1752 officers invited to participate in our survey did so, resulting in a $31 \%$ response rate. However, we are not especially concerned about nonresponse bias, for three reasons. First, the sample demographics closely resemble those of the agency: $90 \%$ of respondents were male (vs. $90 \%$ of the agency), $67 \%$ of respondents were white non-Hispanics (vs. $69 \%$ of the agency), $17 \%$ were 50 years old or older (vs. $14 \%$ of the agency), $44 \%$ were in their 40 s (vs. $40 \%$ of

\footnotetext{
${ }^{2}$ One advantage of analyzing demeanor effects among officers working in a large city is that there are likely greater opportunities for demeanor to shape police-civilian interactions in such locales than in other areas. Nearly a third of all Americans live in cities with populations of at least 100,000, and over $40 \%$ of all serious (index) crimes occur in these cities. Officers may be less likely to know the civilians with whom they interact in large diverse cities than in smaller suburban or rural areas (Decker 1979; Reiss 1971; Weisheit et al. 1994). Furthermore, police use of less lethal force occurs significantly more often during police-civilian interactions involving urban residents, compared to those involving residents of suburban or rural areas (Hyland et al. 2015).
} 
the agency), $32 \%$ were in their 30 s (vs. $36 \%$ of the agency), and $7 \%$ of the sample was in their 20 s (vs. $11 \%$ of the agency). ${ }^{3}$ Second, our study is experimental, and random assignment to conditions controls for selection bias as a threat to the internal validity of findings (Shadish et al. 2002). ${ }^{4}$ Third, meta-analytic evidence shows that "response rates are a poor indicator of nonresponse bias" (Peytchev 2013: 90), explaining just 4\% to $8 \%$ of the variation in bias in survey estimates (Pickett et al. 2018b).

\section{Experimental procedures}

To test whether civilian demeanor has causal effects on officers' cognitions and emotions, we relied on a staple method for analyzing judgment and decision-making: experimental vignettes describing hypothetical scenarios (Mutz 2011; Thaler 2015).

Recognizing the advantages of such vignettes for making causal inferences, scholars increasingly are using them to study policing issues, including civilians' cognitive and emotional reactions to police procedural justice (Barkworth and Murphy 2015; Reisig et al. 2018), and police officers' reactions to civilians (Nix et al. 2017). Responses to hypothetical vignettes have been shown to have construct, concurrent, and predictive validity (Hainmueller et al. 2015; Pogarsky 2004). For this reason, they are frequently used in social science research across disciplines to study such diverse topics as public views about court legitimacy (Gibson 2008), moral outrage about crime (Carlsmith et al. 2002; Darley et al. 2000), and potential offenders' crime-related cognitions and emotions (McGloin and Thomas 2016; Pickett et al. 2018a). In a seminal study, for example, Robinson et al. (2010, 2004) explored the criminogenic effects of legal injustice by asking respondents to imagine they lived in a "hypothetical criminal justice system" where punishments were either just or unjust.

In addition to strengthening causal inferences, the use of experimental vignettes helps to reduce social desirability bias (Auspurg and Hinz 2015). However, the method assumes that respondents know how they would respond in situations. Given the available evidence, this is a reasonable assumption (Hainmueller et al. 2015; Kim and Hunter 1993; Pogarsky 2004). For example, the effects of procedural justice in hypothetical scenarios (Barkworth and Murphy 2015) mirror those observed in realworld experiments (Mazerolle et al. 2013). Similarly, in the case of emotions, research shows that "people are skilled at predicting the valence of their future emotional reactions [and] the specific kinds of emotional reactions they will have" (Wilson and Gilbert 2003: 401).

One important consideration when developing hypothetical vignettes is to ensure their realism (Aguinis and Bradley 2014; Auspurg and Hinz 2015). Therefore, we consulted with several police officers to develop realistic vignettes (i.e., we had them read over our vignettes and provide feedback which we used to make improvements as necessary). Further, because prior research suggests that officers' responses to citizens vary depending on the type of encounter (e.g., traffic stop, suspicious person call)

\footnotetext{
${ }^{3}$ These demographic characteristics also closely approximate national estimates (Reaves 2013).

${ }^{4}$ Of course, random assignment cannot control for nonresponse as a threat to the external validity of results, which would occur only if there is an interaction of selection with the causal effect (Shadish et al. 2002). We revisit the issue of generalizability in the discussion section.
} 
(Mastrofski et al. 2016; Worden and McLean 2017), we developed experimental vignettes for different types of police-civilian encounters. The first two experiments described offense-based encounters, in which the officer observed first-hand a violation (public order or traffic) while on patrol. A third experiment described a dispatchinitiated encounter, in which the officer responded to a suspicious person call. In designing the experiments, we made sure the sample size $(n>100)$ in each cell would exceed the minimally acceptable cell size as recommended by experimental methodologists, and yield at least $80 \%$ statistical power to detect a medium size effect of demeanor (Auspurg and Hinz 2015).

Experiments 1 and 2: offense-based encounters In the first two experiments, we asked the officers to imagine they witnessed an offense while on patrol and then began interacting with the offender(s). The first experiment involved a littering offense coupled with a possible public order violation. Officers were randomly assigned to read one of three vignettes, which varied only by civilian demeanor and compliance: compliant, bad attitude, or noncompliant. Per the demeanor hypothesis, the bad attitude condition is of key theoretical importance. An accurate test of the hypothesis requires that the suspect in the bad attitude condition is hitherto compliant - complying with all initial orders - but disrespectful and hostile toward the officer. Therefore, we stated explicitly in the bad attitude scenario that the suspect complied with initial orders. The text for this scenario was as follows:

One night while you are on patrol, you see two young men who appear to be drunk stumbling down the street. One of the men throws what looks like a beer can on the ground. You walk up and tell them to pick the can up. One of the men says "What are you, the trash police? What the fuck!" But he does pick up the can. Then, he looks back at you and asks "Happy Captain Planet?" They both laugh.

In this condition, the two young men are antagonistic and mock the officer, but nonetheless comply with the officer's command to pick up the litter. In the compliant condition, the young men pick up the can as well, but they are also respectful. Finally, in the noncompliant condition, the young men are disrespectful and refuse to pick up the can (see Appendix A Table 4 for full text of each condition).

For the second experiment, we asked the officers to consider a routine traffic stop for a speeding violation. Similar to before, we randomly assigned the officers to view one of three vignettes that differed only by whether the driver was compliant, had a bad attitude, or noncompliant. Again, the most important task was to separate demeanor from noncompliance, and thus in the bad attitude condition, we stated explicitly that the driver was hitherto compliant:

You pull someone over for driving 10 miles over the speed limit. When you approach the driver's window, he says, "I was going two fucking miles over the speed limit. Don't you have something better to do?" As you start to tell him how fast he was going, he cuts you off and says, "I don't even want to hear it." You ask him for his license and registration. He hands them to you and says "And you wonder why everyone hates the police." 
Here, the driver clearly has a bad attitude - cursing at, interrupting, and belittling the officer-but importantly, he hands over his license and registration, thus initially exhibiting compliance. The compliant driver was courteous and apologetic, saying "Sure, Officer," as he handed over his information. The noncompliant driver was disrespectful and refused to provide his information, and subsequently refused to step out of the vehicle when asked (see Appendix A Table 4).

Experiment 3: dispatch-initiated encounter Our third and final experiment differs from the first two experiments in several ways, which allows us to assess the robustness of findings from the first two experiments. Whereas experiments 1 and 2 involved encounters where the officer witnessed an offense, the third experiment involves an encounter where the officer responds to a suspicious person call and has no knowledge of whether the civilian has committed any offense. In the first two experiments, we randomized the civilians' demeanor, but nothing else. In the third experiment, we also randomized the civilian's race and gender, and the neighborhood context. The purpose was to provide a robustness check against the possibility of information leakage (or construct confounding), which would occur if the officers use the information provided in the experimental vignettes to fill in missing details, and then base their responses on the details they imputed (Dafoe et al. 2015). For example, if the officers associate bad attitudes with high-crime neighborhoods (Holmes and Smith 2012; Smith and Alpert 2007), then what appears to be an effect of demeanor in the bad attitude vignette might instead reflect an effect of the presumed (but unstated) neighborhood context. To rule out this possibility, the potentially relevant details are stated explicitly (and randomly varied) in the third experiment. ${ }^{5}$ The bad attitude condition reads as follows:

While on patrol, you receive a suspicious person call. The dispatcher tells you the suspect is a [white/black] [male/female] in [his/her] 20s, wearing baggy jeans and a t-shirt. [He/she] is walking down the street and looking into car windows in a [wealthy, low-crime/poor, high-crime] neighborhood in [city blinded]. You arrive at the scene and identify the suspect. When you approach [him/her], [he/she] seems uneasy and anxious. You ask for [his/her] name and identification. [He/She] says "What the fuck, I didn't do nothing!" Then, [he/she] tells you [his/her] name and hands you identification. As you begin to question [him/her], [he/she] answers your questions, but is disrespectful, loud, uses profanity, and calls you names.

Though the civilian protests being stopped and questioned, and is loud, profane, and mocks the officer, s/he complies by providing identification and answering the officer's questions. The compliant civilian also does as the officer asks, but is respectful and refers to the officer as sir/ma'am. The noncompliant civilian tells

\footnotetext{
${ }^{5}$ We did not include these additional manipulations in experiments 1 and 2 out of concern that officers might notice if the civilians' race or gender varied from vignette to vignette. We were less concerned about the officers noticing the variations in the civilians' behavior because the overall nature of the interaction (e.g., traffic stop, suspicious person call) differed in each experiment, and the additional details in the third experiment helped to further differentiate (add nuance) to that vignette.
} 
the officer to "go fuck yourself," and refuses to provide any information (see Appendix A Table 4).

\section{Dependent variables}

Immediately following each vignette, we included a series of questions meant to capture officers' cognitive and emotional reactions to the civilians in the scenarios. Using these questions, we constructed four dependent variables.

Suspicion For each experiment, we asked officers, "How trusting or suspicious would you be in this situation?" They were provided six Likert-type response categories: (1) very trusting, (2) trusting, (3) somewhat trusting, (4) somewhat suspicious, (5) suspicious, or (6) very suspicious. Responses were coded so that higher scores reflect greater suspicion.

Antagonistic emotions Following each experiment, we also asked officers to indicate the extent that they would feel: angry, annoyed, or frustrated. For each emotion, respondents could answer (1) not at all, (2) slightly, (3) moderately, or (4) extremely. Principal-factor analyses suggested that for each experiment, responses to these three items loaded onto a single factor with acceptable pattern loadings. ${ }^{6}$ As such, we averaged responses to the items to generate mean scales (alpha $=.88, .89$, and .86 , for each experiment, respectively). Higher scores on the scales reflect more antagonistic emotional reactions on the part of the officers.

Fear We also asked officers as part of each experiment to indicate, "how afraid or unafraid you would be in this situation." Available responses were (1) very afraid, (2) afraid, (3) neither afraid nor unafraid, (4) unafraid, or (5) very unafraid. We reverse coded responses to this question so that higher scores reflect greater emotional fear on the part of the officers.

Perceived danger Finally, in Experiment \#3, we included a fourth dependent variable: perceived danger. Specifically, we asked respondents, "Based on your past experiences, how likely or unlikely is it that as you continue to question this suspect he/she will at some point become physically violent with you?" Response options were (1) very likely, (2) likely, (3) neither likely nor unlikely, (4) unlikely, or (5) very unlikely. We reverse coded responses to this question so that higher scores indicate greater perceived dangerousness of the suspect. This measure provides another cognitive measure of perceived risk (Ferraro 1995), in addition to the suspicion measure (see above).

\section{Analytic strategy}

We estimated linear regression models and, as recommended by experimental methodologists, used randomization inference to conduct the hypothesis tests (Gerber and

\footnotetext{
$\overline{{ }^{6} \text { Experiment } 1 \text { eigenvalue }=2.08}$, loadings .77 to .90 ; experiment 2 eigenvalue $=2.13$, loadings .75 to .90 ; experiment 3 eigenvalue $=1.95$, loadings .70 to .87 .
} 
Green 2012; Keele et al. 2012). Randomization inference is an exact test of the sharp null hypothesis of no effect, which is based on the random assignment within the finite sample, rather than on large sample theory. It requires no parametric distributional assumptions, and is valid with non-normally distributed outcomes, in the presence of outliers and high leverage, and with nonprobability samples, regardless of sample size (Gerber and Green 2012). ${ }^{7}$

Our third experiment is a 3 (behavior) $\times 2$ (race) $\times 2$ (gender) $\times 2$ (neighborhood) factorial vignette, and thus we include each of the experimental manipulations as a categorical variable in the regression models. ${ }^{8}$ Given that we test our hypotheses in three experiments, the false positive rate is inflated. Accordingly, we use a Bonferronicorrected alpha of .0167 as the threshold for considering a finding statistically significant.

\section{Results}

Before proceeding to the main statistical analysis, it is instructive to first explore visually how the officers' responses to each of the survey questions vary across the three behavior conditions (compliant, bad attitude, and noncompliant) in each experiment. The responses for each of our cognitive and emotional measures are depicted graphically in Fig. 1. The first panel shows responses for experiment 1, the second for experiment 2, and the bottom panel shows those for experiment 3. In Fig. 1, for visual clarity, we collapse each measure into binary form, whereby 1 indicates an affirmative response for experiencing the cognition or emotion ( 0 otherwise). The figure displays the percentage of respondents who fall into the " 1 " category for each outcome, by behavior condition across the experiments. Although the three antagonistic emotion measures (anger, annoyance, frustration) are combined for the main analysis, we evaluate them separately here.

The results in Fig. 1 are striking. First, inspection of the figure reveals that all of the outcomes are lowest when the suspect is compliant and has a good attitude. Very few officers report antagonistic emotions, fear, or perceived danger when the civilian is compliant. And except in experiment 3, where the vignette describes a suspicious person call, very few officers report being suspicious of compliant civilians.

Second, it is clear that when the civilian complies but has a bad attitude, all of the outcomes increase, and this is consistent across all three experiments. With a disrespectful civilian, many officers indicate they would feel some level of suspicion (70$97 \%$ ), anger (17-37\%), annoyance (62-85\%), and frustration (36-64\%). Some officers even say they would be afraid or very afraid of the civilian (4-11\%). In the third experiment, $37 \%$ of officers feel the suspect with a bad attitude is potentially dangerous. It bears emphasizing that although the civilians in the bad attitude vignettes are disrespectful and hostile, they have hitherto complied with all officer commands. This serves as preliminary evidence that civilian demeanor has an effect on officers independent of legal compliance.

\footnotetext{
${ }^{7}$ For the randomization inference, we used the command "ritest" in Stata (Heß 2017).

${ }^{8}$ Consistent with best practices for analyzing experimental data, we did not control for respondent characteristics in our models, an approach that "can be badly flawed" (Berk et al. 2013: 170; see also Freedman 2008).
} 


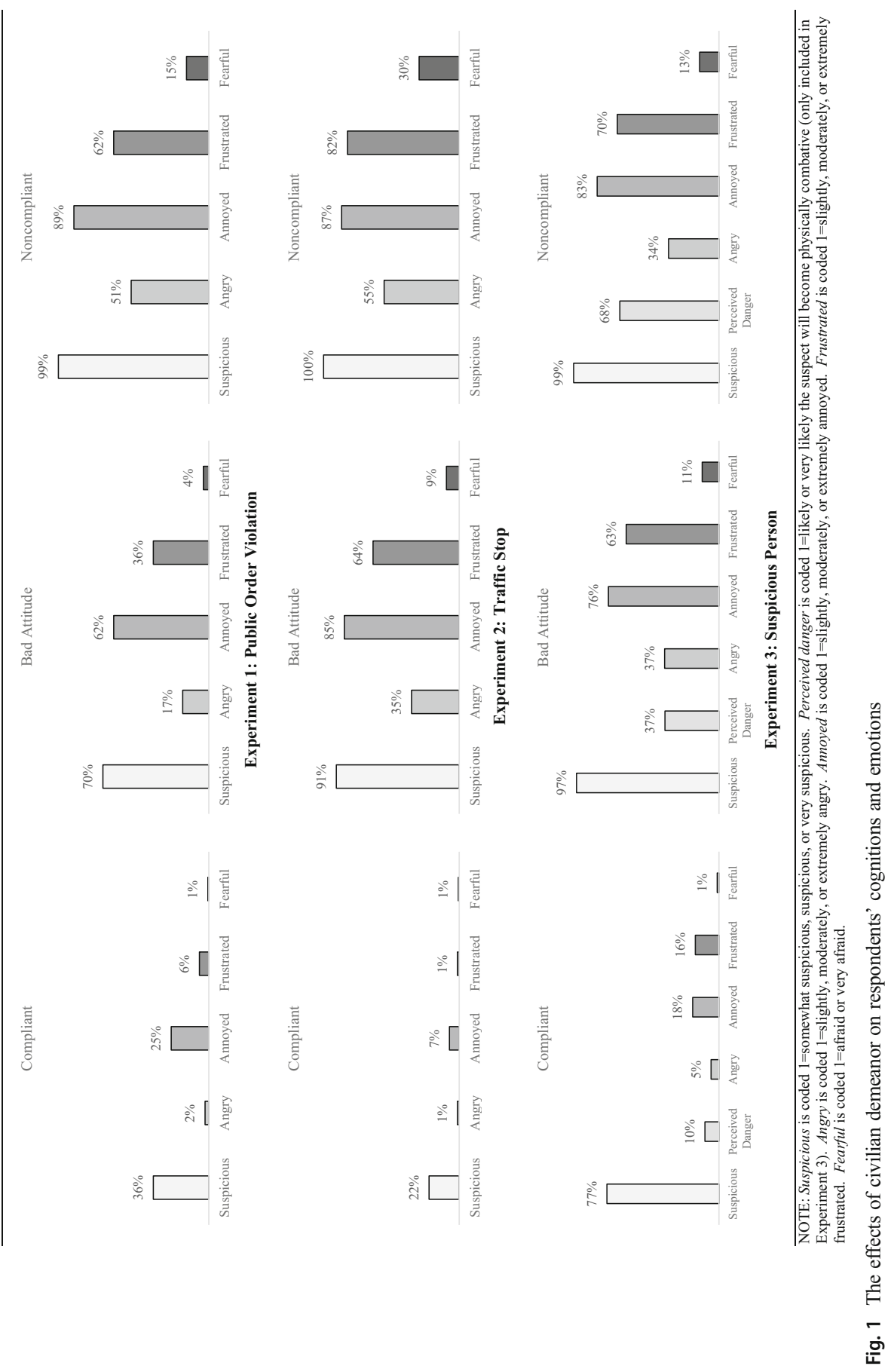


Third, with one exception, all of the outcomes are highest when the civilian is noncompliant. As would be expected, officers respond even more negatively to noncompliant civilians than to those who are compliant but have bad attitudes, suggesting that a refusal to follow lawful orders matters above and beyond failing the attitude test. Next, we assess the statistical significance of these effects, starting with the offense-based experiments.

\section{Offense-based encounters (experiments 1 and 2)}

The regression results for experiments 1 and 2 are shown in Table 1. Recall that our first experiment involved a littering violation in the presence of the officer, and the second experiment entailed a traffic stop. Models 1 and 4 in Table 1 show the results for the first outcome, suspicion, in each experiment. In both experiments, relative to the compliant (with a good attitude) condition, when the civilians are compliant but have bad attitudes it significantly and substantially increases officers' suspicion $(b=.632$ and 1.354, $p<.001$, respectively). These effects are statistically significant using a Bonferronicorrected alpha of .0167 to account for multiple testing. The effects of outright noncompliance are even larger than those of having a bad attitude. The civilians' behavior accounts for 45-65\% of the variation in officers' suspicion in experiments 1 and 2.

Models 2 and 5 in Table 1 show the regression results for the second outcome, antagonistic emotions, for each offense-based experiment. As with the suspicion outcome, the bad attitude manipulation has a profound effect on officers' antagonistic emotions in both experiments. Relative to encounters with compliant civilians with good attitudes, officers experience much higher levels of anger, frustration, and annoyance when interacting with compliant civilians who are disrespectful and hostile. These effects are

Table 1 Effects of demeanor and noncompliance in offense-based encounters

\begin{tabular}{|c|c|c|c|c|c|c|}
\hline \multirow[b]{3}{*}{ Experimental manipulations } & \multicolumn{6}{|c|}{ Experiment 1: Public Order Violation } \\
\hline & \multicolumn{2}{|c|}{ Model 1: Suspicion } & \multicolumn{2}{|c|}{ Model 2: Antagonistic Emotions } & \multicolumn{2}{|c|}{ Model 3: Fear } \\
\hline & $b$ & $p$ value & $b$ & $p$ value & $b$ & $p$ value \\
\hline Compliant (reference) & - & - & - & - & - & - \\
\hline Bad attitude & .632 & .000 & .366 & .000 & -.011 & .929 \\
\hline Noncompliant & 1.764 & .000 & .922 & .000 & .444 & .000 \\
\hline$R^{2}$ & .451 & & .293 & & .062 & \\
\hline \multirow[t]{3}{*}{$N$} & 460 & & 460 & & 459 & \\
\hline & \multicolumn{6}{|c|}{ Experiment 2: Traffic Stop } \\
\hline & \multicolumn{2}{|c|}{ Model 4: Suspicion } & \multicolumn{2}{|c|}{ Model 5: Antagonistic Emotions } & \multicolumn{2}{|c|}{ Model 6: Fear } \\
\hline Experimental manipulations & $b$ & $p$ value & $b$ & $p$ value & $b$ & $p$ value \\
\hline Compliant (reference) & - & - & - & - & - & - \\
\hline Bad attitude & 1.354 & .000 & .892 & .000 & .371 & .000 \\
\hline Noncompliant & 2.631 & .000 & 1.274 & .000 & .798 & .000 \\
\hline$R^{2}$ & .654 & & .397 & & .150 & \\
\hline $\mathrm{N}$ & 482 & & 482 & & 482 & \\
\hline
\end{tabular}

Notes: Unstandardized regression coefficients are shown 
substantial and statistically significant $(b=.366$ and $.892, p<.001$, respectively), even using a Bonferroni-corrected alpha of .0167 to account for multiple testing. Officers' antagonistic emotions are much higher still when civilians are noncompliant than when they are compliant. In both experiments, the civilians' behavior accounts for a sizable portion (29-40\%) of the variation in officers' antagonistic emotions.

Models 3 and 6 in Table 1 show the regression results for the third outcome, fear, for each offense-based experiment. Here, the bad attitude manipulation only has a significant positive effect in the traffic stop $(b=.371, p<.001)$, where officers report being significantly more afraid on average when confronting a compliant civilian with a bad attitude, relative to a compliant civilian with a good attitude. The effect of the bad attitude manipulation is not significant and is in the wrong direction $(b=-.011$, $p=.929$ ) in the littering vignette. However, in both experiments, civilian noncompliance has a substantial and statistically significant positive effect on fear $(b=.444$ and $.798, p<.001$, respectively). The civilians' behavior in experiments 1 and 2 only accounts for approximately $6-15 \%$ of the variation in officers' emotional fear.

\section{Dispatch-initiated encounter (experiment 3)}

Table 2 presents the results of our third experiment, which involved the officer responding to a suspicious person call. Recall that for this experiment we

Table 2 Effects of demeanor and noncompliance in a dispatch-initiated encounter

\begin{tabular}{|c|c|c|c|c|c|c|c|c|}
\hline & \multicolumn{8}{|c|}{ Experiment 3: Suspicious Person } \\
\hline & \multicolumn{2}{|c|}{$\begin{array}{l}\text { Model 1: } \\
\text { Suspicion }\end{array}$} & \multicolumn{2}{|c|}{$\begin{array}{l}\text { Model 2: } \\
\text { Perceived } \\
\text { Danger }\end{array}$} & \multicolumn{2}{|c|}{$\begin{array}{l}\text { Model 3: } \\
\text { Antagonistic } \\
\text { Emotions }\end{array}$} & \multicolumn{2}{|c|}{ Model 4: Fear } \\
\hline Experimental Manipulations & $b$ & $p$ value & $b$ & $p$ value & $b$ & $p$ value & $b$ & $p$ value \\
\hline Civilian behavior & - & - & - & - & - & - & - & - \\
\hline Compliant (reference) & - & - & - & - & - & - & - & - \\
\hline Bad attitude & .946 & .000 & .679 & .000 & .701 & .000 & .076 & .385 \\
\hline Noncompliant & 1.297 & .000 & 1.184 & .000 & .790 & .000 & .227 & .008 \\
\hline Civilian race & - & - & - & - & - & - & - & - \\
\hline White (reference) & - & - & - & - & - & - & - & - \\
\hline Black & -.146 & .058 & .047 & .547 & -.062 & .300 & .079 & .271 \\
\hline Civilian gender & - & - & - & - & - & - & - & - \\
\hline Female (reference) & - & - & - & - & - & - & - & - \\
\hline Male & .115 & .137 & .211 & .003 & .041 & .525 & .150 & .041 \\
\hline Neighborhood context & - & - & - & - & - & - & - & - \\
\hline Wealthy, low-crime (reference) & - & - & - & - & - & - & - & - \\
\hline Poor, high-crime & .176 & .023 & .131 & .084 & .069 & .267 & .091 & .214 \\
\hline$R^{2}$ & .338 & & .284 & & .251 & & .035 & \\
\hline$N$ & 498 & & 498 & & 497 & & 498 & \\
\hline
\end{tabular}

Notes: Unstandardized regression coefficients are shown 
randomized suspect race, gender, and neighborhood context in addition to suspect behavior. Model 1 displays the effects of these manipulations on the first outcome, suspicion. Relative to encounters involving compliant suspects, officers reported being significantly more suspicious of the suspect who had a bad attitude $(b=.946, p<.001)$. Similar to the previous experiments, officers reported being even more suspicious of the noncompliant suspect $(b=1.297, p<.001)$. Each of these effects remain statistically significant when using the Bonferronicorrected alpha of .0167 . The model explained roughly one-third of the variance in suspicion.

For the third experiment, we also included a second measure of respondents' cognitions-perceived danger posed by the suspect at some point during the encounter. The results are presented in Model 2 of Table 2. Officers were more likely to perceive the suspect as dangerous if s/he had a bad attitude or was outright noncompliant, relative to compliant. The effects were substantial and statistically significant ( $b=.679$ and $1.184, p<.001$, respectively). Each of these effects remain significant when using the Bonferroni-corrected alpha threshold. Officers also perceived male suspects as more dangerous than females $(b=.211$, $p=.003)$. This is unsurprising given that males are far more likely than females to assault and kill police officers, according to the FBI's 2017 Law Enforcement Officers Killed and Assaulted data. ${ }^{9}$ The model as a whole explains approximately $28 \%$ of the variance in officers' cognitive assessment of the likelihood that the suspect will at some point become physically combative.

In Model 3, we regressed our outcome antagonistic emotions onto each of the experimental manipulations. Relative to encounters with compliant civilians who had good attitudes, officers said they would experience much higher levels of anger, frustration, and annoyance when faced with civilians who had bad attitudes or were noncompliant. Again, the observed effects are substantial and significant ( $b=.701$ and $.790, \mathrm{p}<.001$, respectively), even when using the Bonferronicorrected alpha threshold. Notably, neither the suspect's race or gender, nor the neighborhood context in which the encounter took place exerted any significant effects. As a whole, the model accounted for roughly $25 \%$ of the variation in officers' antagonistic emotions.

Model 4 shows the effects of the experimental manipulations on our fourth outcome, fear. In this instance, the effect of the bad attitude manipulation was statistically nonsignificant $(b=.076, p=.385)$. That is, in the suspicious person encounter, officers were not significantly more fearful of suspects who had a bad attitude, relative to suspects who were compliant. On the other hand, officers were more fearful of noncompliant suspects, and the effect was significant, even when using the Bonferroni correction $(b=.227, p=.008)$. Together, the experimental manipulations explained about $4 \%$ of the variation in officers' fear. With these results in mind, we now turn to a discussion of the theoretical and policy implications of our study.

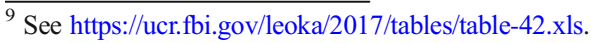


Table 3 Hypothesis test results for each experiment

\begin{tabular}{llll}
\hline Hypothesis & Experiment & & \\
\cline { 2 - 4 } & $\begin{array}{l}\text { \#1 Public order } \\
\text { violation }\end{array}$ & $\# 2$ Traffic stop & $\begin{array}{l}\text { \#3 Suspicious } \\
\text { person }\end{array}$ \\
\hline $\begin{array}{l}\text { 1. Disrespectful civilians will arouse greater } \\
\text { suspicion among officers than respectful } \\
\text { civilians, independent of legal compliance }\end{array}$ & Supported & Supported & Supported \\
$\begin{array}{l}\text { 2. Independent of legal compliance, disrespectful } \\
\text { civilians will evoke more antagonistic } \\
\text { emotions (i.e., anger, annoyance, frustration) } \\
\text { among officers than respectful civilians }\end{array}$ & Supported & Supported & Supported \\
$\begin{array}{l}\text { 3. Officers will be more fearful of civilians who } \\
\text { are disrespectful than those who are } \\
\text { respectful, independent of legal compliance }\end{array}$ & Not supported & Supported & Not supported \\
$\begin{array}{l}\text { 4. Relative to respectful civilians, officers will } \\
\text { perceive a greater risk of danger when dealing } \\
\text { with disrespectful civilians, independent of } \\
\text { legal compliance }\end{array}$ & N/a & N/a & Supported \\
\hline
\end{tabular}

\section{Conclusion}

Why is it important to identify the specific socio-psychological effects of civilian demeanor on police officers? Beyond the goal of theoretical development and accuracy, there are several practical reasons. Perhaps the most significant is that different cognitions and emotions will likely have different behavioral consequences. Suspicion, for example, may lead officers to further question, search, or detain (e.g., momentarily handcuff) civilians. Antagonistic emotions - such as anger, frustration, and annoyance - might cause officers to disrespect civilians or respond to them more punitively (e.g., arresting them or using coercive force). Fear and perceived danger might increase the likelihood of use-of-force errors, such as mistaking a cell phone for a handgun, or misinterpreting an innocuous movement as furtive, and shooting an unarmed suspect (Sherman 2018). Additionally, the different cognitive and emotional reaction officers have when confronting civilians with bad attitudes may be responsive to different policies and types of training. For example, the interventions that are effective for limiting antagonistic emotions may differ from those needed to reduce overreactions resulting from fear.

Our findings provide the clearest and strongest evidence to date that independent of legal compliance, demeanor influences the way officers think and feel in police-civilian interactions (see Table 3 for a summary of findings). When civilians have a bad attitude, officers are more likely to be suspicious, perceive danger, and experience various antagonistic emotions such as anger, frustration, and annoyance. These findings were consistent across three different experiments involving routine police-civilian interactions. We observed in Experiment 3 that these effects remained substantial and significant even when we provided officers 
with additional (randomized) information about the civilian's race and gender, as well as the neighborhood context in which the encounter occurred. The results with respect to fear were more complex, as we will discuss shortly. But in all three experiments, officers reported being more fearful of civilians who were noncompliant in addition to having a bad attitude. Collectively then, our findings illuminate the importance of studying the situational effects of demeanor and noncompliance on officers, and provide a framework for better understanding police decision-making during interactions with civilians.

Let us consider the implications of our results separately for each of the specific cognitions and emotions examined herein. Our findings with respect to the effects of demeanor on officers' antagonistic emotions suggest that agencies should explore ways to offset the anger and frustration that may arise when dealing with someone who is compliant but behaves like a "certifiable asshole" (Van Maanen 1978: 229). Antagonistic emotions matter because they are likely to foster various coping efforts, which may include aggressive behavioral adaptations, to relieve these emotions. Indeed, antagonistic emotions may explain the findings in prior studies that officers dealing with disrespectful civilians are less apt to de-escalate (James et al. 2018), and more likely to disrespect (Mastrofski et al. 2002), use coercive force on (Engel et al. 2000; Garner et al. 2002), and arrest civilians (Lundman 1996; Worden and Shepard 1996). From a general strain perspective, these discretionary behaviors are likely coping mechanisms used by officers in response to the anger and frustration they experience upon being disrespected. This is problematic because the law does not regulate attitudes; civilians have a right to be assholes - indeed, this is what distinguishes demeanor conceptually from noncompliance (Klinger 1994).

Theoretically, officers should be less reliant on aggressive or punitive means for adapting to the strain of dealing with civilians who have bad attitudes if alternative forms of "conventional social support" are available (Agnew 1992: 72). Organizational justice may be one form of conventional social support that increases officers' ability to respond prosocially, or at least non-punitively, to disrespectful civilians. As James Q. Wilson (1967) observed over 50 years ago, agencies can inspire morale among employees even in light of external influences, like civilian disrespect, which they cannot control. One such way, he argued, was "careful enforcement of internal regulations in a way that demonstrates that the leadership stands behind the men without fear or favoritism" (p. 157). As but one example, while dealing with hostile civilians who demand to speak with a supervisor or threaten to file a complaint, officers who are confident their supervisors will treat them fairly may feel less pressure to dole out "street-level justice" (Smith and Visher 1981). One promising avenue for reducing the influence of antagonistic emotions on police decision-making, then, is for agencies to strive to maintain an organizationally fair work environment for their officers. Indeed, some research suggests that officers who feel their supervisors are respectful, transparent, listen to their concerns, and otherwise treat them fairly tend to be less cynical and distressed, and in turn are less reliant on coercive force (Trinkner et al. 2016). The evidence also suggests officers are less likely to engage in misconduct (Wolfe 
and Piquero 2011) and more committed to treating civilians respectfully (Bradford and Quinton 2014; Tankebe 2014; Trinkner et al. 2016) when they believe their agency treats them fairly. Given this work and our findings, the next step is for future research to replicate our experiment and examine whether officers who perceive greater organizational justice are less likely to report antagonistic emotions in response to civilians with bad attitudes, and to allow such emotions to influence their decisions about how to treat civilians.

Our findings also strongly support the contention that officers are more suspicious of disrespectful than respectful civilians, ceteris paribus (Bayley 1995; Skolnick 1966). Theoretically, the representativeness heuristic, whereby officers judge civilians' proclivities based on how well their behavior resembles that of the stereotypical criminal (see Tversky and Kahneman 1974), is likely at the root of this effect. If the prototypical criminal in officers' minds has a bad attitude, then officers will judge civilians who have bad attitudes to have a high probability of being criminal (Kahneman 2011). One problem with such heuristic judgments is they result in an insensitivity both to the quality of relevant evidence and to statistical base-rate information (Kahneman 2011), and can lead to stereotype amplification, where real-world associations become exaggerated in the minds of decision makers (Quillian and Pager 2010). Another problem is that although disrespect on its own is not a criminal offense, if officers perceive that it signifies a person is suspicious and potentially dangerous, they may nonetheless feel the need to gain control over the encounter. Thus, in even absent antagonistic emotions, the effects of demeanor on suspicion might lead officers to conduct searches or detain disrespectful individuals, sometimes under legally precarious circumstances. The danger is that, as Crank (2014: 152) notes, "a welltrained but distrustful officer who is convinced of someone's guilt, erases the line between unmasking guilt and creating it." Some civilians, particularly those who have not committed an offense, may become upset when an officer attempts to search or momentarily handcuff them, and passively or actively resist, which in turn increases the likelihood of coercive force being used (Bolger 2015).

Because suspicion is a predisposition that officers acquire via the socialization process (Skolnick 1966), the demeanor-suspicion relationship has training implications. First, training emphasizing that bad attitudes violate no laws may help to reduce officers' reliance on the attitude test to judge civilian suspiciousness and dangerousness. Such training may also have the added benefit of helping to reduce antagonistic emotions by countering the view that a bad attitude is a moral violation. Second, training exercises (e.g., simulations) meant to hone officers' perceptual skills - namely, their ability to establish probable cause without pointing to someone's bad attitude as evidence s/he is hiding something - may be useful. At a minimum, increasing officers' awareness of their tendency to rely on demeanor as a heuristic to judge the suspiciousness and dangerousness of civilians may help them avoid common judgmental biases and improve decision-making accuracy.

With respect to fear, our findings were more complex. Only in one of the three experiments - the traffic stop scenario - were officers significantly more fearful of the 
civilian with a bad attitude, relative to the compliant civilian. Yet, this effect was statistically significant even using a Bonferroni-corrected alpha to account for the fact that we tested the hypothesis three times. This suggests that the effect of civilian demeanor on certain officer emotions, like fear, may vary by the type of encounter. Consistent with this interpretation, the bad attitude manipulation failed to significantly affect fear in the suspicious person experiment, despite exerting a large effect on perceived danger. Recall that fear is a function not just of perceived risk but also of perceived control or predictability (Jackson 2011). That civilian demeanor significantly affected fear only in the traffic experiment is perhaps attributable to the uncertainty involved in traffic stops (Bayley and Garofalo 1989). For example, in this scenario, compared to the others, it would be more difficult for officers to discern if the driver has a weapon hidden within reach (e.g., between the seats). Additionally, many of the videos used to train officers about the dangers of interacting with civilians involve traffic stops, such as the video of the shooting of Deputy Kyle Dinkheller in 1998 (Lake 2017).

Although in many situations fear is warranted and even advantageous, officers who experience fear in response to civilians with bad attitudes may also be more likely to escalate the situation (e.g., by taking an aggressive stance, or drawing and pointing their firearm). Elevated fear may also be associated with perceptual distortions (Klinger 2004; Klinger and Brunson 2009), which could result in mistake-of-fact shootings (Sherman 2018). Periodic training exercises that require officers to make quick decisions while in a state of heightened fear may improve officer decision-making in real world encounters. More broadly, a better understanding of how civilian demeanor interacts with the situational context to influence fear among officers is important for efforts to reduce overreactions and mistakes that may result from increased fearfulness and that may be especially likely in certain environments.

Our study was the first to demonstrate the causal effects of civilian demeanor, net of compliance, on officers' cognitions and emotions. The next step for researchers is to evaluate whether the cognitions and emotions examined herein influence behavioral outcomes (e.g., search, arrest, use of force), while keeping in mind the difficulties of establishing causality in mediation analysis, even in experiments (Bullock et al. 2010). Studies are also needed that explore whether situational effects, such as those observed here, have broader impacts - such as increasing immersion into the police culture (Paoline and Gau 2018) or general anger (Bishopp et al. 2018). As Toch (1996):107) points out, "incident-centered approaches become person-centered approaches when one compiles incidents over an officer's career and sees the officer as a composite of the incidents in which he or she has been involved." In other words, to what extent does a single encounter with a disrespectful civilian have the capacity to influence an officer's perception of civilians more broadly or adherence to different policing styles?

Before closing, a number of limitations of our study deserve mention, which provide opportunities for future research. For starters, we sampled officers from a single agency at one point in time, and only $31 \%$ of the sampled officers chose to participate in our experiments. Although sample selection is not a threat to the 
internal validity of our findings, it would undermine their external validity if (and only if) it interacted with the causal effects examined herein (Shadish et al. 2002). Thus, while we believe our findings will generalize to other agencies and across time, it is possible that they will not, and future research is needed that tests this possibility. Whenever possible, researchers should consider incentivizing their surveys in order to improve their response rate (Singer 2002). Researchers might also consider administering their surveys in person to maximize their response rate (Nix et al. 2017b), while keeping in mind this could result in increased social desirability bias (Tourangeau and Yan 2007).

Our study also relied on a single method-hypothetical text vignettes - that while commonly used for analyzing judgment and decision-making, is not perfect. Experimental vignettes ensure causal ordering and enhance internal validity, which is necessary to test the demeanor hypothesis, but they may not evoke as strongly the cognitions and emotions officers would experience in realworld interactions. Future studies should thus attempt to replicate our findings using alternative methods - such as video simulations (e.g., James et al. 2018) or role-playing exercises (e.g., Hine et al. 2018)—wherein civilians' demeanor is randomized and officers are immediately interviewed afterward about what they were thinking and feeling. Such a methodology would permit researchers to draw conclusions about the relationship between officers' thoughts and feelings and their behavioral responses. Similarly, while there is evidence that humans are good at anticipating their emotional reactions (Wilson and Gilbert 2003), physiological indicators of emotions would also be useful. Researchers might monitor officers' heart rates and alpha brain waves during simulations to provide a more objective measure of their emotional responses and perceived threat (see, e.g., James et al. 2014). Given that many police-civilian interactions involve multiple officers, such simulations could also involve a second officer who serves as backup, which might reduce the primary officer's fear or perceived danger. These are just a few of many avenues future research on this topic could explore.

There is observational evidence dating as far back as the 1950s that what civilians say and do while interacting with police officers influences their outcomes. Our study contributes to this literature by providing experimental evidence that independent of legal compliance, civilian disrespect has substantial causal effects on officers' cognitions and emotions. In our experiments, officers faced with civilians who had bad attitudes grew more suspicious, perceived greater danger, felt more antagonistic emotions, and in some circumstances became more fearful. Continued exploration of these socio-psychological responses in officers will help shed light on variation in officer behaviors when interacting with civilians, as well as identify promising policy avenues for improving police decision-making. Wilson (1967: 158) emphasized, "the fact that the police can no longer take for granted that noncriminal citizens are also nonhostile citizens may be the most important problem which even the most proficient department must face." We agree and hope our results spur on additional theoretical and empirical work aimed at better understanding the effects of demeanor on police decision-making. 
Acknowledgments The authors are grateful to Scott Wolfe, Emily Wright, Ben Steiner, Bobby Brame, Gillian Pinchevsky, and the anonymous reviewers for their helpful feedback on earlier versions of this manuscript.

\section{Appendix}

Table 4 Full text of all conditions in each experimental vignette
Experiment 1
Public order
One night while you are on patrol, you see two young men who appear to be drunk stumbling down the street. One of the men throws what looks like a beer can on the ground. You walk up and tell them to pick the can up. One of the men says ... violation
Compliant "Sure, officer" and picks up the can
Bad attitude "What are you, the trash police? What the fuck!" But he does pick up the can. Then, he looks back at you and asks "Happy Captain Planet?" They both laugh.
Noncompliant "Fuck you," and the other man flips you the bird. They keep walking without picking up the can.

Experiment 2 You pull someone over for driving 10 miles over the speed limit. When you approach the driver's Traffic stop window, he says ...

Compliant "Officer, I think I was only going two miles over the speed limit.” You tell him how fast he was driving. He says "sorry about that, I guess I did not realize how fast I was going." You ask him for his license and registration. He says "sure, officer," and hands them to you.

Bad Attitude "I was going two fucking miles over the speed limit. Do not you have something better to do?" As you start to tell him how fast he was going, he cuts you off and says, "I do not even want to hear it." You ask him for his license and registration. He hands them to you and says "And you wonder why everyone hates the police."

Noncompliant "I was going two fucking miles over the speed limit. Do not you have something better to do?" You tell him how fast he was going, and ask for his license and registration. He tells you to "go fuck yourself. I'm not giving you anything." You tell him to step out of the car, and he says "fuck you."

Experiment 3 While on patrol, you receive a suspicious person call. The dispatcher tells you the suspect is a Suspicious person [white/black] [male/female] in his/her 20s, wearing baggy jeans and a t-shirt. He/she is walking down the street and looking into car windows in a [wealthy, low-crime/poor, high-crime] neighborhood in \{city blinded\}. You arrive at the scene and identify the suspect. When you approach [him/her], [he/she] seems uneasy and anxious. You ask for [his/her] name and identification. [He/She] says ...

Compliant "Sure, officer," tells you [his/her] name and hands you identification. As you begin to question [him/her], [he/she] is compliant and respectful, and refers to you as sir/ma'am.

Bad attitude "What the fuck, I did not do nothing!" Then, [he/she] tells you [his/her] name and hands you identification. As you begin to question [him/her], [he/she] answers your questions, but is disrespectful, loud, uses profanity, and calls you names.

Noncompliant "Go fuck yourself. I did not do nothing." As you go to question [him/her] further, [he/she] cuts you off and says, "You can stop that shit. I know my rights. I ain't saying dick to you."

Open Access This article is distributed under the terms of the Creative Commons Attribution 4.0 International License (http://creativecommons.org/licenses/by/4.0/), which permits unrestricted use, distribution, and reproduction in any medium, provided you give appropriate credit to the original author(s) and the source, provide a link to the Creative Commons license, and indicate if changes were made. 


\section{References}

Agnew, R. (1992). Foundation for a general strain theory of crime and delinquency. Criminology, 30, 47-88.

Aguinis, H., \& Bradley, K. J. (2014). Best practice recommendations for designing and implementing experimental vignette methodology studies. Organizational Research Methods, 17, 351-371.

Alpert, G. P., \& Dunham, R. G. (2004). Understanding police use of force: officers, suspects, and reciprocity. New York, NY: Cambridge University Press.

Auspurg, K., \& Hinz, T. (2015). Factorial survey experiments. Thousand Oaks, CA: Sage.

Barkworth, J. M., \& Murphy, K. (2015). Procedural justice policing and citizen compliance behaviour: the importance of emotion. Psychology, Crime \& Law, 21, 254-273.

Bayley, D. (1995). Getting serious about police brutality. In P. C. Stenning (Ed.), Accountability for criminal justice: selected essays (pp. 93-109). Toronto: University of Toronto Press.

Bayley, D., \& Garofalo, J. (1989). The management of violence by police patrol officers. Criminology, 27, 126.

Becker, H. (1963). Outsiders. New York, NY: Free Press.

Bennett, R. R. (1976). The necessity of critical examination of criminal justice concepts: a case of the "symbolic assailant". Journal of Police Science and Administration, 4, 82-87.

Berk, R., Pitkin, E., Brown, L., Buja, A., George, E., \& Zhao, L. (2013). Covariance adjustments for the analysis of randomized field experiments. Evaluation Review, 37, 170-196.

Berkowitz, L. (1993). Aggression: its causes, consequence, and control. Philadelphia, PA: Temple University Press.

Bishopp, S. A., Leeper Piquero, N., Worrall, J. L., \& Piquero, A. R. (2018). Negative affective responses to stress among urban police officers: a general strain theory approach. In Deviant Behavior E-pub ahead of print. https://www.tandfonline.com/doi/abs/10.1080/01639625.2018.1436568.

Black, D. (1976). The behavior of law. New York, NY: Academic Press.

Black, D., \& Reiss, A. J. (1970). Police control of juveniles. American Sociological Review, 35, 63-77.

Bolger, P. C. (2015). Just following orders: a meta-analysis of the correlates of American police officer use of force decisions. American Journal of Criminal Justice, 40, 466-492.

Bradford, B., \& Quinton, P. (2014). Self-legitimacy, police culture and support for democratic policing in an English constabulary. British Journal of Criminology, 54, 1023-1046.

Brown, M. K. (1988). Working the street: police discretion and the dilemmas of reform. New York, NY: Russell Sage Foundation.

Bullock, J. G., Green, D. P., \& Ha, S. E. (2010). Yes, but what's the mechanism? (Don't expect and easy answer). Journal of Personality and Social Psychology, 98, 550-558.

Carlsmith, K. M., Darley, J. M., \& Robinson, P. H. (2002). Why do we punish? Deterrence and just deserts as motives for punishment. Journal of Personality and Social Psychology, 83, 284-299.

Crank, J. P. (2014). Understanding police culture. New York, NY: Routledge.

Dafoe, A., Zhang, B., \& Caughey, D. (2015). Confounding in survey experiments. In Working paper Available online at: http://www.sas.rochester.edu/psc/polmeth/papers/confounding.pdf. Accessed 26 May 2018.

Darley, J. M. (2009). Morality in the law: the psychological foundations of citizens' desires to punish transgressions. Annual Review of Law and Social Science, 5, 1-23.

Darley, J. M., Carlsmith, D. M., \& Robinson, P. H. (2000). Incapacitation and just deserts as motives for punishment. Law and Human Behavior, 24, 659-683.

de Quervain, D. J. F., Fischbacher, U., Treyer, V., Schellhammer, M., Schnyder, U., et al. (2004). The neural basis of altruistic punishment. Science, 305, 1254-1258.

Decker, S. (1979). The rural county sheriff: an issue in social control. Criminal Justice Review, 4, 97-111.

Dillman, D. A., Smyth, J. D., \& Christian, L. M. (2014). Internet, phone, mail, and mixed-mode surveys: the tailored design method (4th ed.). Hoboken, NJ: Wiley.

Donner, C. M., Fridell, L. A., \& Jennings, W. G. (2016). The relationship between self-control and police misconduct: a multi-agency study of first-line police supervisors. Criminal Justice and Behavior, 7, 841862.

Dunham, R. G., \& Alpert, G. P. (2009). Officer and suspect demeanor: a qualitative analysis of change. Police Quarterly, 12, 6-21.

Engel, R. S., Sobol, J. J., \& Worden, R. E. (2000). Further exploration of the demeanor hypothesis: the interaction effects of suspects' characteristics and demeanor on police behavior. Justice Quarterly, 17, $235-258$. 
Engel, R. S., Klahm, C. F., \& Tillyer, R. (2010). Citizens' demeanor, race and traffic stops. In S. K. Rice \& D. Michael (Eds.), Race, ethnicity, and policing: new and essential readings (pp. 287-308). White. New York: New York University Press.

Engel, R. S., Tillyer, R., Klahm, C. F., \& Frank, J. (2012). From the officer's perspective: a multilevel examination of citizens' demeanor during traffic stops. Justice Quarterly, 29, 650-683.

Fehr, E., \& Fischbacher, U. (2004). Third-party punishment and social norms. Evolution and Human Behavior, 25, 63-87.

Ferraro, K. F. (1995). Fear of crime: interpreting victimization risk. Albany, NY: SUNY Press.

Freedman, D. A. (2008). On regression adjustments to experimental data. Advances in Applied Mathematics, 40, 180-193.

Garner, J. H., Maxwell, C. D., \& Heraux, C. G. (2002). Characteristics associated with the prevalence and severity of force used by the police. Justice Quarterly, 19, 705-746.

Gerber, A. S., \& Green, D. P. (2012). Field experiments: design, analysis, and interpretation. New York: W.W. Norton \& Company.

Gibson, J. L. (2008). Challenges to the impartiality of state supreme courts: legitimacy theory and "new style" judicial campaigns. American Political Science Review, 102, 59-75.

Hainmueller, J., Hangartner, D., \& Yamamoto, T. (2015). Validating vignette and conjoint survey experiments against real-world behavior. PNAS, 112, 2395-2400.

Heß, S. (2017). Randomization inference with Stata: a guide and software. Stata Journal, 17, 630-651.

Hine, K. A., Porter, L. E., Westera, N. J., Alpert, G. P., \& Allen, A. (2018). What were they thinking? Factors influencing police recruits' decisions about force. In Policing and Society E-pub ahead of print. https://www.tandfonline.com/doi/full/10.1080/10439463.2018.1432612.

Holmes, M. D., \& Smith, B. W. (2012). Intergroup dynamics of extra-legal police aggression: an integrated theory of race and place. Aggression and Violent Behavior, 17, 344-353.

Hyland, S., Langton, L., \& Davis, E. (2015). Police use of nonfatal force, 2002-11 (No. NCJ 249216). Washington, DC: Bureau of Justice Statistics Retrieved from https://www.bjs. gov/content/pub/pdf/punf0211.pdf.

Jackson, J. (2011). Revisiting risk sensitivity in the fear of crime. Journal of Research in Crime and Delinquency, 48, 513-537.

Jackson, J., \& Gray, E. (2010). Functional fear and public insecurities about crime. British Journal of Criminology, 50, 1-22.

Jacobs, D., \& O'Brien, R. M. (1988). The determinants of deadly force: a structural analysis of police violence. American Journal of Sociology, 103, 837-862.

James, L., Klinger, D., \& Vila, B. (2014). Racial and ethnic bias in decisions to shoot seen through a stronger lens: experimental results from high-fidelity laboratory simulations. Journal of Experimental Criminology, 10, 323-340.

James, L., James, S., \& Vila, B. (2018). Testing the impact of citizen characteristics and demeanor on police officer behavior in potentially violent encounters. Policing: An International Journal, 41, $24-40$.

Kahneman, D. (2011). Thinking fast and slow. New York, NY: Farrar, Straus and Giroux.

Kahneman, D., Knetsch, J. L., \& Thaler, R. H. (1986). Fairness and the assumptions of economics. Journal of Business, 59, S285-S300.

Keele, L., McConnaughy, C., \& White, I. (2012). Strengthening the experimenter's toolbox: statistical estimation of internal validity. American Journal of Political Science, 56, 484-499.

Kim, M.-S., \& Hunter, J. E. (1993). Relationships among attitudes, behavioral intentions, and behavior: a meta-analysis of past research, part 2. Communication Research, 20, 331-364.

Klinger, D. A. (1994). Demeanor or crime? Why "hostile" citizens are more likely to be arrested. Criminology, $32,475-493$.

Klinger, D. A. (1996). More on demeanor and arrest in Dade County. Criminology, 34, 61-82.

Klinger, D. A. (2004). Into the kill zone: a cop's eye view of deadly force. San Francisco, CA: Jossey-Bass.

Klinger, D. A., \& Brunson, R. K. (2009). Police officers' perceptual distortions during lethal force situations: informing the reasonableness standard. Criminology \& Public Policy, 8, 117-140.

Lake, T. (2017). The trigger and the choice. In Part 1: Two decades later, a traffic stop on a country road is still teaching police officers about deadly force - and the cost of hesitation. CNN State Available online at: http://www.cnn.com/interactive/2017/politics/state/kyle-dinkheller-police-video/.

Lundman, R. J. (1974). Routine police arrest practices: a commonweal perspective. Social Problems, 22, 127141.

Lundman, R. J. (1994). Demeanor or crime? The Midwest City police-citizen encounters study. Criminology, $32,631-656$. 
Lundman, R. J. (1996). Demeanor and arrest: additional evidence from previously unpublished data. Journal of Research in Crime and Delinquency, 33, 306-323.

MacDonald, J. M., Kaminski, R. J., Alpert, G. P., \& Tennenbaum, A. N. (2001). The temporal relationship between police killings of civilians and criminal homicide: a refined version of the danger-perception theory. Crime \& Delinquency, 47, 155-172.

Mastrofski, S. D., Worden, R. E., \& Snipes, J. B. (1995). Law enforcement in a time of community policing. Criminology, 33, 359-363.

Mastrofski, S. D., Reisig, M. D., \& McCluskey, J. D. (2002). Police disrespect toward the public: an encounter-based analysis. Criminology, 40, 519-551.

Mastrofski, S. D., Jonathan-Zamir, T., Moyal, S., \& Willis, J. J. (2016). Predicting procedural justice in policecitizen encounters. Criminal Justice and Behavior, 43, 119-139.

Mazerolle, L., Antrobus, E., Bennet, S., \& Tyler, T. R. (2013). Shaping citizen perceptions of police legitimacy: a randomized field trial of procedural justice. Criminology, 51, 33-63.

McGloin, J. M., \& Thomas, K. J. (2016). Incentives for collective deviance: group size and changes in perceived risk, cost, and reward. Criminology, 54, 459-486.

Miller, D. T. (2001). Disrespect and the experience of injustice. Annual Review of Psychology, 52, 527-553.

Miller, L. (2004). Good cop_-bad cop: problem officers, law enforcement culture, and strategies for success. Journal of Police and Criminal Psychology, 19, 30-48.

Mutz, D. C. (2011). Population-based survey experiments. Princeton, NJ: Princeton University Press.

Nix, J., \& Pickett, J. T. (2017). Third-person perceptions, hostile media effects, and policing: developing a theoretical framework for assessing the Ferguson effect. Journal of Criminal Justice, 51, 24-33.

Nix, J., Pickett, J. T., Wolfe, S. E., \& Campbell, B. A. (2017a). Demeanor, race, and police perceptions of procedural justice: evidence from two randomized experiments. Justice Quarterly, 34, 1154-1183.

Nix, J., Pickett, J. T., Baek, H., \& Alpert, G. P. (2017b). Police research, officer surveys, and response rates. In Policing \& Society E-pub ahead of print. https://www.tandfonline.com/doi/full/10.1080 /10439463.2017.1394300.

Novak, K. J., \& Engel, R. S. (2005). Disentangling the influence of suspects' demeanor and mental disorder on arrest. Policing: An International Journal of Police Strategies \& Management, 28, 493-512.

Paoline, E. A. (2003). Taking stock: toward a richer understanding of police culture. Journal of Criminal Justice, 31, 199-214.

Paoline, E. A. (2004). Shedding light on police culture: an examination of officers' occupational attitudes. Police Quarterly, 7, 205-236.

Paoline, E. A., \& Gau, J. M. (2018). Police occupational culture: testing the monolithic model. Justice Quarterly, 35, 670-698.

Peytchev, A. (2013). Consequences of survey nonresponse. The Annals of the American Academy of Political and Social Science, 645, 88-111.

Pickett, J. T., \& Baker, T. (2017). Punishment and solidarity? An experimental test of the educative-moralizing effects of legal sanctions. Journal of Experimental Criminology, 13, 217-240.

Pickett, J. T., \& Nix, J. (2019). Demeanor and police culture: theorizing how civilian cooperation influences police officers. Policing: An International Journal Online first: https:/www.emeraldinsight. com/doi/full/10.1108/PIJPSM-09-2018-0133.

Pickett, J. T., Roche, S. P., \& Pogarsky, G. (2018a). Toward a bifurcated theory of emotional deterrence: fear and deterrence. Criminology, 56, 27-58.

Pickett, J. T., Cullen, F. T., Bushway, S. D., Chiricos, T., \& Alpert, G. (2018b). The response rate test: nonresponse bias and the future of survey research in criminology and criminal justice. The Criminologist, $43,7-11$.

Piliavin, I., \& Briar, S. (1964). Police encounters with juveniles. American Journal of Sociology, 70, 20162214.

Pogarsky, G. (2004). Projected offending and contemporaneous rule-violation: implications for heterotypic continuity. Criminology, 42, 111-135.

Quillian, L., \& Pager, D. (2010). Estimating risk: stereotype amplification and the perceived risk of criminal victimization. Social Psychology Quarterly, 73, 79-104.

Reaves, B. A. (2013). Local police departments, 2013: personnel, policies, and practices (no. NCJ 248677). Washington, DC: Bureau of Justice Statistics Retrieved from https://www.bjs.gov/content/pub/pdf/lpd13 ppp.pdf.

Reisig, M. D., McCluskey, J. D., Mastrofski, S. D., \& Terrill, W. (2004). Suspect disrespect toward the police. Justice Quarterly, 21, 241-268.

Reisig, M. D., Mays, R. D., \& Telep, C. W. (2018). The effects of procedural injustice during police-citizen encounters: a factorial vignette study. Journal of Experimental Criminology, 14, 49-59. 
Reiss, A. J. (1971). The police and the public. New Haven, CT: Yale University Press.

Reynolds, P. D., \& Helfers, R. C. (2017). Differences in perceptions of organizational fairness based on job characteristics among police officers. American Journal of Criminal Justice E-pub ahead of print. https://link.springer.com/article/10.1007/s12103-017-9404-8.

Robinson, P. H., Goodwin, G. P., \& Reisig, M. D. (2010). The disutility of injustice. NYU Law Review, 85, 1940-2033.

Sanfey, A. G., Rilling, J. K., Aronson, J. A., Nystrom, L. E., \& Cohen, J. D. (2003). The neural basis of economic decision-making in the ultimatum game. Science, 300, 1755-1758.

Shadish, W. R., Cook, T. D., \& Campbell, D. T. (2002). Experimental and quasi-experimental designs for generalized causal inference. Belmont, CA: Wadsworth Cengage Learning.

Sherman, L. W. (2018). Reducing fatal police shootings as system crashes: research, theory and practice. Annual Review of Criminology, 1, 421-449.

Singer, E. (2002). The use of incentives to reduce nonresponse in household surveys. In R. M. Groves, D. A. Dillman, J. L. Eltinge, R. J. A. Little, et al. (Eds.), Survey nonresponse (pp. 163-177). New York, NY: Wiley.

Skogan, W. G. (2015). Surveying police officers. In M. D. Maltz \& S. K. Rice (Eds.), Envisioning criminology: researchers on research as a process of discovery. New York, NY: Springer.

Skolnick, J. H. (1966). Justice without trial: law enforcement in democratic society. New York, NY: Free Press.

Smith, D. A. (1984). The organizational context of legal control. Criminology, 22, 19-38.

Smith, M. R., \& Alpert, G. P. (2007). Explaining police bias: a theory of social conditioning and illusory correlation. Criminal Justice and Behavior, 34, 1262-1283.

Smith, D. A., \& Visher, C. A. (1981). Street-level justice: situational determinants of police arrest decisions. Social Problems, 29, 167-177.

Spano, R. (2005). Potential sources of observer bias in police observational data. Social Science Research, 34 , 591-617.

Spano, R. (2006). Observer behavior as a potential source of reactivity: describing and quantifying observer effects in a large-scale observational study of police. Sociological Methods \& Research, 34, 521-553.

Sykes, R. E., \& Clarke, J. P. (1975). A theory of deference exchange in police civilian-encounters. American Journal of Sociology, 81, 584-600.

Tankebe, J. (2014). The making of 'democracy's champions': understanding police support for democracy in Ghana. Criminology \& Criminal Justice, 14, 25-43.

Thaler, R. H. (2015). Misbehaving: the making of behavioral economics. New York, NY: W.W. Norton \& Company.

Toch, Hans. 1996. The violence-prone police officer. In Police violence: understanding and controlling police abuse of force (pp. 94-112), eds. William A. Geller and Hans Toch. New Haven, CT: Yale University Press.

Tourangeau, R., \& Yan, T. (2007). Sensitive questions in surveys. Psychological Bulletin, 133, 859-883.

Tourangeau, R., Conrad, F. G., \& Couper, M. P. (2013). The science of web surveys. New York, NY: Oxford University Press.

Trinkner, R., Tyler, T. R., \& Goff, P. A. (2016). Justice from within: the relations between a procedurally just organizational climate and police organizational efficiency, endorsement of democratic policing, and officer well-being. Psychology, Public Policy, and Law, 22, 158-172.

Tversky, A., \& Kahneman, D. (1974). Judgment under uncertainty: heuristics and biases. Science, 185, 1124 1131.

Van Maanen, J. (1978). The asshole. In P. K. Manning \& J. Van Maanen (Eds.), Policing: a view from the street (pp. 221-238). Pacific Palisades, CA: Goodyear Publishing Company.

Warr, M. (2009). Safe at home. Contexts, 8, 46-51.

Weisburd, D., Greenspan, R., Hamilton, E. E., Williams, H., \& Bryant, K. A. (2000). Police attitudes toward abuse of authority: findings from a national study. Washington, DC: National Institute of Justice.

Weisheit, R. A., Wells, L. E., \& Falcone, D. N. (1994). Community policing in small town and rural America. Crime \& Delinquency, 40, 549-567.

Weitzer, R. (2015). American policing under fire: misconduct and reform. Society, 52, 475-480.

Westfall, J., \& Yarkoni, T. (2016). Statistically controlling for confounding constructs is harder than you think. PLoS One, 11, e0152719. https://doi.org/10.1371/journal.pone.0152719.

Westley, W. A. (1953). Violence and the police. American Journal of Sociology, 59, 34-41.

Westley, W. A. (1970). Violence and the police: a sociological study of law, custom, and morality. Cambridge, MA: MIT Press. 
Wilson, J. Q. (1967). Police morale, reform, and citizen respect: the Chicago case. In D. J. Bordua (Ed.), The police: six sociological essays (pp. 137-162). New York: John Wiley \& Sons Inc..

Wilson, T. D., \& Gilbert, D. T. (2003). Affective forecasting. In M. P. Zanna (Ed.), Advances in experimental social psychology. San Diego, CA: Academic Press.

Wolfe, S. E., \& Piquero, A. R. (2011). Organizational justice and police misconduct. Criminal Justice and Behavior, 38, 332-353.

Worden, R. E., \& McLean, S. J. (2017). Mirage of police reform: procedural justice and police Legitimacy. Oakland, CA: University of California Press.

Worden, R. E., \& Shepard, R. L. (1996). Demeanor, crime, and police behavior: a reexamination of the police services study data. Criminology, 34, 83-105.

Worden, R. E., Shepard, R. L., \& Mastrofski, S. D. (1996). On the meaning and measurement of suspects' demeanor toward the police: a comment on "demeanor and arrest". Journal of Research in Crime and Delinquency, 33, 324-332.

Publisher's note Springer Nature remains neutral with regard to jurisdictional claims in published maps and institutional affiliations.

Justin Nix is an assistant professor in the School of Criminology and Criminal Justice at the University of Nebraska Omaha. He received his $\mathrm{PhD}$ in Criminology and Criminal Justice in 2015 from the University of South Carolina. His research interests include procedural justice and police officer decision-making. Some of his recent work has appeared in Justice Quarterly, Crime \& Delinquency, and Criminology and Public Policy. Justin is the corresponding author and can be contacted at jnix@unomaha.edu.

Justin Pickett is an associate professor in the School of Criminal Justice at the State University of New York at Albany. He received his PhD in Criminology in 2011 from Florida State University. He is the 2015 recipient of the American Society of Criminology's Ruth Shonle Cavan Young Scholar Award. His research interests include police-community relations, public opinion, survey research methods, and theories of punishment.

Renée Mitchell is a sergeant with the Sacramento Police Department. She received her PhD in 2017 from the University of Cambridge where she was a Jerry Lee Scholar. Her research interests include place-based policing, legitimacy, de-escalation, and body-worn cameras. She currently serves as President of the American Society of Evidence-Based Policing.

\section{Affiliations}

\section{Justin Nix ${ }^{1}$ - Justin T. Pickett ${ }^{2} \cdot$ Renée J. Mitchell $^{3}$}

1 School of Criminology and Criminal Justice, University of Nebraska Omaha, Omaha, USA

2 School of Criminal Justice, SUNY, University at Albany, Albany, USA

3 Sacramento Police Department and Institute of Criminology, University of Cambridge, Cambridge, UK 